Artha-Journal of Social Sciences

2019, Vol. 18, No. 3, 25-42

ISSN 0975-329X | https:/ / doi: 10.12724/ajss.50.2

\title{
Decolonising Cultural Studies
}

\author{
Rashmi Sawhney*
}

\section{Abstract}

Written as a reflective account emerging from the process of reviewing and revamping an $\mathrm{MA}$ in English and Cultural Studies at Christ (Deemed to be University), Bangalore, in the year 2018-19, this essay takes the form of a tapestry woven out of four separate but related inquiries. Section I reflects upon the experience of having taught introductory courses in Cultural Studies (henceforth CS) in India and Ireland separated by a gap of 15 years, and germane questions of cultural specificity and curricula. Section II provides an overview of the available narratives of CS within India, focusing on the distinctive approach taken in each account. Section III looks at the relationship between CS, Postcolonial Studies (henceforth PS) and Subaltern Studies (henceforth SS), as they developed in play with one another in 1980s England and America. And Section IV comments on some wider institutional and creative practices of relevance, and the implications these hold for possible future directions of CS. In totality, the article attempts to assess what transformative work it might be possible to do through CS in the future.

Keywords: Cultural Studies in India, Localising Curriculum

\section{Monochromatic Narratives}

In 2003, while doing my PhD in Ireland, I was asked to teach some modules of an Introduction to Cultural Studies course to BA

* School of Business Studies and Social Sciences (SBSSS), CHRIST (Deemed to be University), India; rashmi.sawhney@christuniversity.in 
students in the School of Languages and Cultural Studies at the University of Limerick. Being one of three PhD scholars of colour in the department (the other two being an Egyptian boy and a Nigerian girl), and the only South Asian, it is hardly surprising that I was asked to focus on the Postcolonial studies and 'Third World' Feminism bits along with the sections on CS in India. The person who had enlisted me for this job, Professor Joachim Fischer, a scholar of German and CS, had recommended going through Ziauddin Sardar and Borin Van Loon's (1998) Introducing Cultural Studies: A Graphic Guide, as a useful starting point. This wonderful little book, scripted together with the rare combination of a sense of humour and a stringent critique, offered an accessible introduction to the 'discipline' at that point.

When I taught those modules to a class of mostly white Irish students, along with a handful of (again, mostly white) exchange students from Europe, I went with the account laid out in the book, which is the standard narrative we have now inherited: CS originated as a British working class project through the Birmingham School, and its foundations were primarily established by the Historian E P Thompson, Sociologist and Literary Critic Richard Hoggart and Marxist Theorist and Novelist Raymond Williams in the 1960s. It then spread to various countries like America, Canada, France, India, and Australia, in the 1980s, with each location developing its own 'national' variant of the discipline. So my white Irish students, learnt to marvel at the power of the British working class resistance and their demands for cultural legitimation, without really connecting this history to the Irish experience at all. There was a hushed silence about the fact that the Birmingham centre had in fact closed down in 2002; one taught and studied about British CS as if no wind had been taken out of its sails by the unfortunate closure of the Birmingham School.

It did not strike me at the time to wonder why there was no emphasis on how CS was being developed, or might be practiced in the Irish context, especially given that the course was being taught in the School of Languages and Cultural Studies, which meant that the discipline had already started becoming institutionalised. What is even more remarkable, is that Britain's 400 year colonisation of Ireland, and the physical proximity of the two countries (including 
that the land of Northern Ireland, which is still a part of the United Kingdom, flows seamlessly into the Republic of Ireland, with no border control or check) did not result in CS's migration across the Irish Sea. The few 'Irish Cultural Studies' courses that are available in the Republic, mainly emphasise the historical transformations in 'Irish culture' from an ancient to the modern period, including some introduction to Irish literature, cinema, music and theatre. In fact, the more one thinks about this, the more deeply it sinks in, that the Birmingham School CS project, was quite specifically an English project, which did not seem to interest either Scotland, Wales, or Ireland very much.i This begs the question then, that if the discipline managed to migrate across far seas, travelling to distant lands like USA, Australia and India, then why was its impact on England's immediate (and English speaking) peripheries so negligent?

Fifteen years later, I again found myself teaching an 'Introduction to Cultural Studies' course on an M.A in English and Cultural Studies programme at Christ University, Bangalore, in the south of India. I hadn't paid much attention to Sardar and van Loon's book in this interim period, during which I had completed my PhD in Film and Cultural Studies and taught at several different universities in Europe and in India. What struck me was how little the narrative had changed even though fifteen years had passed. A considerable amount of the syllabus was dedicated to introducing Indian students to the history of the Birmingham school. Not surprisingly, my students, who came from big and small cities from all parts of India, and belonged to both middle class and working class families, did not seem to feel terribly excited by the nuances of English working class culture, or the idea of garrulous political discussions by the lads in the local, on their way back after a hard day's work. This time, I made it a point to tell my students that the historiography of CS obfuscated the fact that the Birmingham Centre had closed down almost two decades ago, under not entirely pleasant circumstances.

It would be unfair to say that the course was totally inattentive to the Indian context. There were some essays which added an 'Indian perspective' on sports or popular culture, but the sense of an Indian practice of CS, or indeed a history of CS in India, was largely 
missing from the syllabus. The irony of this was exacerbated by the fact that in 1998 Sardar and van Loon had claimed that "if Vinay Lal's extensive bibliography was anything to go by, one can be forgiven for thinking that like cricket, Cultural Studies is an Indian invention accidentally discovered by the British" (Sardar and van Loon 1998:155-56). The fact that Lal's substantial annotated bibliography along with a lengthy introduction had been published in 1996 is evidence to the fact that the contours and shades of a subcontinental CS were already being designed and defined, even if the extent to which these discussions extended beyond India, to Pakistan, Bangladesh, Sri Lanka or Nepal, is debatable. It is important to clarify that my intention is not to critique any one particular course or another, but to draw attention to the absence of adequate discussion about or any consensus on what could constitute a CS syllabus in India. Since my colleagues and I have been in the process of reviewing our own MA programme in English and Cultural Studies this year, it is an opportune moment to take stock of what one could possibly teach as CS in India. ${ }^{\text {ii }}$

\section{Histories and Possibilities of a Regional Cultural Studies}

Any of the theories of 'Region' could be mobilised to think through the question of how to relocate CS more meaningfully within its more immediate contexts. One of the starting points towards exploring these possibilities is to look at the available narratives of CS within the regional/national context. There are three significant narratives of the Indian historiography of CS available to us. The first is outlined by Sardar and van Zoon and indicates that the origin of CS in India can be traced back to the cultural studies of science in the 1970s through the work of scholars like Jit Singh Uberoi (1978), Claude Alvares (1979) and Ashis Nandy(1980), subsequently joined by Shiv Vishwanathan $(1885,1997)$ who ensured that "radical scholarship in India was guided by the belief that all knowledge is political intervention" (1998, p. 157).

Sardar and van Zoon identify three loci through which CS developed in India: 1. The Centre for the Study of Developing Societies (CSDS, Delhi); 2. The Centre of Contemporary Studies (CCS) at the Nehru Memorial Library, popularly also known as 'Teen Murti'; and 3. The Subaltern Studies Group based in multiple 
locations across the world, and their journal, Subaltern Studies: Writings on Indian History and Society published inconsistently from 1982-2005. Key scholars associated with each of these sites are identified and accompanied by a pithy introduction to their core intellectual agendas. These include: Rajni Kothari, Ashish Nandy and D L Seth at CSDS; Aijaz Ahmed at CCS; and the Subaltern Historians Ranjit Guha, Deepesh Chakravarty, Gyanendra Pandey, Sumit Sarkar, Shahid Amin and Gayatri Chakravorty Spivak based at various institutions in Delhi and Calcutta, as well as universities in England, Australia and North America.

The second narrative on the development of CS in India is offered in a 2008 report by Ratheesh Radhakrishnan, "Cultural Studies in India: A Preliminary Report on Institutionalisation," published by the Higher Education Cell of the Centre for the Study of Culture and Society, Bangalore. Radhakrishnan traces a history of Cultural Studies through its institutionalisation in various higher education centres across India, offering critical comments on their individual contexts and pedagogic and research emphases. These include: The Centre for Studies in Social Sciences (CSSS), Kolkata, which has been holding an annual CS workshop since 1995; the English and Foreign Languages University (EFLU), Hyderabad, which established MA and PhD programmes in Cultural Studies in 2001; the Department of Cultural Studies established in 1995 in Tezpur University, Assam; the School of Media and Cultural Studies (SMCS) at the Tata Institute of Social Sciences, Mumbai; and the Centre for the Study of Culture and Society (CSCS), Bangalore, which unfortunately had to close down a few years ago. In addition to these, CS is taught in a number of Humanities and Social Science departments at Kuvempu University, Delhi University, Bangalore University, the Indian Institutes of Technology and several others. Each of these institutions teach a mix of Critical and Cultural Theory along with courses on popular culture, film and media studies, anthropology, literature, political science etc. Radhakrishnan raises the question of what could constitute a common imaginary for CS in India when institutions are offering their own unique and varied interpretations of the discipline? He speculates that it might indeed be the emphasis on the local context (for e.g. the curriculum at Tezpur focuses on the North East, SMCS at TISS mainly develops its pedagogy through ethnographic 
research and documentary practice, and EFLU foregrounds questions of caste and gender) that might provide a commonality to defining the discipline and practice of CS in India.

Several of the documents that Radhakrishnan draws attention to (such as CFPs for the CSSS conferences etc), include allusions to the originary period of CS, loosely tracing it back to the mid-1970s, when post Emergency, the cookie crumbled, so to speak. In a talk presented in 2012 as part of a workshop on Curatorial Studies organised by the India Foundation for the Arts and the School of Creative Expressions at Ambedkar University, Susie Tharu suggests that the 1970s marked a pivotal turn in the nature of politics as well as of democracy, both influenced by the emergence of the 'popular,' giving voice to formerly marginalised communities of women and Dalits.iii Thus, the history of Cultural Studies as scholarly work which saw knowledge production as political, precedes its institutionalisation in the mid-1990s, by about two decades.

The third account of CS in India is offered by Madhava Prasad, in his essay "Cultural Studies in India," written, as Prasad states "when Cultural Studies in India was attempting to define its place and role in academia," and most recently published in Genealogies of the Asian Present (Niranjana \& Xiaoming, 2015). Prasad provides an overview of the socio-political contexts which set the conditions for CS, including the fading aura of the Queen's English along with the emergence of what Rita Kothari and Rupert Snell (2011) call 'chutnifed English', as larger numbers of students from classes and castes previously outside the pale of third level education make their way onto Literature programmes. Arguing that CS has always taken on a 'national' flavour in each new location, Prasad attempts to trace what constitutes 'national culture' and its changing discourse, from the 1940s onwards. In doing so, he constructs a panoramic landscape, citing scholarship ranging from anthropology to film and media studies, and from political science to history, among others. Prasad's central point is to call attention to the need for CS to engage with 'our time' or the contemporary, rather than invest in attempting to resurrect a colonial and precolonial 'past time', as evidenced in the parallel growth of 
Postcolonial Studies, which in many ways, has become an inextricable part of the narrative of CS.

A fourth narrative which does not reflect in any of the three accounts mentioned so far is the work mobilised through the InterAsia Cultural Studies network. The Inter-Asia Cultural Studies (IACS) project was started in the 1990s in order to foster collaborations between scholars and researchers across various Asian countries. Its member institutions consist of universities and research organisations from Taiwan, China, Korea, Indonesia, India, Bangladesh, Japan, and Australia. Among the various initiatives of the Society are the publication of the journal Inter-Asia Cultural Studies, the holding of a migrating annual conference, the organising of a summer school, and facilitating student and faculty exchanges between its member institutions.iv The express objective of the consortium is to re-center CS outside the Anglo-American axis, participating in cultural politics at a local level, but with an international agenda.

The consortium is based on the methodological premise of bifocality, which is captured poignantly in the words of one of its founding members, the Taiwanese intellectual, Kuan-Hsing Chen, who states, "The more I go to Seoul, the more I understand Taipei," constructing a critical inter-Asia subjectivity, drawing on local critical intellectual traditions while making global links with other cultural studies networks (Niranjana \& Xiaoming, 2015, p. 4). Drawing upon the Japanese Sinoligist Takeyuchi Yoshima's concept of "Asia as Method," Hsing Chen explains that the objective of IACS is to move beyond the postcolonial critique of the West as the constant reference for knowledge production by shifting reference points to places in Asia (ibid., p. 57). Further building upon this, Tejaswini Niranjana rallies for "Asia as methodology," to focus on: knowledge production about Asian locations premised on the multiplication of frames of reference; comparative research addressing the conditions of emergence of specific phenomenon in different locations; visiblising the normative frame of the 'West' as the reference point; and the study of trans-cultural analogous concepts such as Partha Chatterjee's political society and Kuan-Hsing Chen's minjian/grassroot intellectuals (ibid., pp. 5-6). 
Tracing conceptual frameworks, especially as they evolve within vernacular local languages is especially important, as this enables one to extrapolate CS as more than a 'discipline-in-formation' to a certain 'way of being in and responding to the world.' Thereby, the specific conjuncture which resulted in British Cultural studies can exist simultaneously with CS conjunctures in other parts of the world, without the burden of a singular origin-narrative. The Japanese Sociologist and Cultural Theorist, Shyunya Yoshimi argues that under the condition of the geopolitics of global knowledge in the 20th century, cultural studies was required as a critical movement and should be acknowledged as having plural forms, with multiple points of origin across the world:

I think that the wider meaning of cultural studies in Japan can be seen in the 1920s or even late 1910s. There are two major reasons . . . the growth of popular culture and cultural industries. . . mediated by reproductive media, namely cinema, popular music, radio, records and department stores. . . [and] ... the expansion of the Marxist approach in 1920s Japan. As evidence of these two historical aspects we can see the rise of popular culture research/studies from cultural Marxist approaches in the 1920s. These studies were called 'Minshugorakuron' (popular entertainment studies) or 'Minshubunkaron' (popular culture studies). ... They examined how the new working class consumed cinema in their everyday life. They had the hypothesis that working class people could produce popular culture under the current dominant conditions of media culture, namely cinema. . . . What I want to say here is that cultural studies did not only occur in the UK, but it occurred in many parts of the world. (Yoshimi, 2006, pp. 310-11)

The desire to highlight these multiple points (and times) of origin is not a drive towards one-upmanship, or a plot to appropriate an intellectual/activist history that belongs to Britain, but rather, a gesture towards the recognition that the currency of CS lies precisely in its demands for localisation, including in tracing its 
history or pre-history in different locations. If one approaches the global history of CS as a cartograph, one might observe British CS being simultaneously in dialogue with emergent variants of CS in other parts of the world, rather than as the currently prevalent linear narrative of Birmingham to Delhi-Tokyo-Sydney etc. To understand some of these cartographic strokes from our perspective here in India, it may be useful to revisit the interhistories of Cultural Studies, Postcolonial Studies and Subaltern Studies, all of which criss-cross over each other's terrains in 1970s England, and to some extent, North America.

\section{Chequered Paths: Cultural Studies, Subaltern Studies, Postcolonial Studies}

Urban legend says that the foundational text of PS was Edward Said's Orientalism, published in 1978. At the time of its publication, Said held a tenured post at Columbia University, which he joined in 1963, after completing his PhD in Literature from Harvard. Frantz Fanon, the French-Martinique psychiatric and political philosopher, whose work is germinal within PS, had already published Black Skins, White Masks in 1952, and The Wretched of the Earth in 1961. In 1951, the Caribbean scholar Stuart Hall, had left Jamaica to board that legendary flight to England, a journey which has by now acquired mythic proportions. In an interview with the sociologist Les Back, Hall recounts:

Okay, so I was in flight. Then I 'discovered my' subject, or rather it discovered me. My subject was coming out of the station at Paddington. That has been my subject, ever since: the diaspora. ... So that is really where cultural studies began for me. It didn't begin with Raymond Williams, it began with my struggle to come to terms with that experience, which is when I first discovered I was a black intellectual. I'd never called myself black ever in my life, nor did most Jamaican people. Many, many people in Jamaica, including lots of people who were black, did not think of themselves in the way in which people after the late 60s came to think of themselves as black. So it was a discovery for me, a 
rediscovery of the Caribbean in new terms, and a rediscovery of my thinking about culture, and a rediscovery of the black subject. (Hall and Back 2009, p. 662)

Hall, who emerged as an iconic scholar of the Birmingham School, spent his entire lifetime writing about issues that were core concerns of Postcolonial Theory as well. After completing his MA in English from Oxford, Hall registered for a PhD but never finished it, choosing his political life over an academic one. However, by 1960, he had established the New Left Review (NLR), as Founding Editor, along with E. P Thompson, Dorothy Thompson, and John Saville, resigning from the Board only a year later. In a retrospective account of the early years of the New Left Review, a publication that was born through the merger of The Reasoner (which the Thompsons, Dorris Lessig, John Saville and others edited) and The University Left Review (ULR, which Hall edited at Oxford), Hall describes the differences that marked the Board of the NLR as constituted by differing political formations (pre-war and post-war), as well as the different geographical and symbolic locations occupied by the Reasoner (based in Yorkshire) and the ULR (based along the cosmopolitan London-Oxford axis).v By 1964, Hall had co-written The Popular Arts with Paddy Whannel from the British Film Archive, proposing a serious study of film as entertainment, as a consequence of which, Richard Hoggart invited him to join the Birmingham Centre in the very first year of its establishment. By 1968, Hall had become the Director of the Centre. In comparison, Raymond William's landmark book, Culture and Society was published in 1958, and E. P. Thompson's The Making of the English Working Class was published in 1963. Thus, although Hall was younger in age compared to what has been eulogised as the founding Trinity (i.e. Hoggart, Thompson and Williams) of the Birmingham School in any number of accounts, narrativizing the origins of British CS mainly as a 'working class' project obfuscates the encounter between an indigenous white working class and a coloured, immigrant, middle class. The stories of these encounters remain scattered outside the canonical historiography of Cultural Studies, and are worth pulling together here. 
An important figure within this UK landscape is Ranjit Guha, now eulogised as the founding editor of Subaltern Studies. Given Guha's lifelong investment into recovering the agency of peasants, an impressionable reader might assume that he lived and worked in the rural hinterlands of India for his lifetime. It might therefore come as a surprise to some, that a large part of his scholarship developed in England, where he lived and taught from 1959-1980, first at the University of Manchester and then at the University of Sussex. Towards the end of the 1970s, Ranajit Guha along with Shahid Amin, David Arnold, Partha Chatterjee, David Hardiman and Gyanendra Pandey -- all London-based historians - initiated a series of conversations on the state of South Asian historiography. Their main critique was directed towards the elitist nationalist histories of India, which they sought to democratise through the SS project, by writing about peasant insurgencies as an important part of Indian national history.

The two predominant influences on Guha and the Subaltern project were the 'history from below' approach being developed by scholars like E. P. Thompson and Eric Hobsbawm in the UK, and the work of Italian Marxist activist and intellectual, Antonio Gramsci. While it was in the UK that Guha encountered the work of Hobsbawm and Thompson, Gramsci had been introduced to him in the 1950s - at a time when Gramsci's work was not widely known to Marxists in the West -- by the Bengali historian Susobhan Sarkar, who taught Guha at Presidency College in Calcutta. vi In 1968, Sarkar published "The Thoughts of Gramsci", continuing his explorations independent of the Subaltern studies group. Part of the reason for the tremendous popularity of Gramsci was that the Marxist focus on the industrial working class as the sole agent of radical social change, excluded large parts of the world which weren't organised into the bourgeoise/proletariat framework, and Gramsci's 'subaltern' provided them the agency that had been

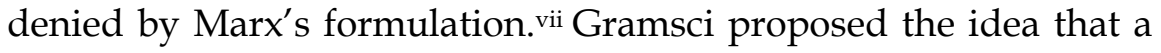
bloc of subordinated and oppressed classes - the subaltern -- rather than a unified working class, was the bedrock of revolution. This kind of nexus of solidarity worked much better for Indian societies, which were far too complex to be understood through the classical Marxist model. Also, the Maoist peasant insurgency of Naxalbari in Bengal, made a deep mark on many Indian intellectuals working in 
the 1970s, some of who (including Guha) were actively involved with Maoist student organisations. Although the term 'Urban Naxal' has come to be bandied about with much derision by the BharatiyaJanta Party and its supporters today, in the 1970s, the Naxalbari movement helped establish the foundations of serious intellectual projects such as this one, whose objective was to understand the relationship between 'revolutionary theory and mass struggle in India' (Chaturvedi, 2000, p. x).

Having said that, it can never be stated often enough that the Subaltern Studies project was rather a male bastion, and other than the longer-term involvement of translator and Postcolonial Theorist Gayatri Chakravarty-Spivak, female participation remained restricted to a few essays by the Calcutta-based art historian Tapati Guha-Thakurta and the Hyderabad-based Literary and Cultural Theorist Susie Tharu.viii Spivak's now widely mis-quoted article, "Can the Subaltern Speak?" rather than a question to be taken literally, is really a critique of the masculinist project of the SS group. It is more than slightly ironic, that several of the Subaltern historians have been idolised, just in the manner of the elite within the nationalist movement, whom they set out to critique!

Although SS began as a project with the clear agenda of seeking legitimisation for peasant insurgencies as part of 'national' histories, invoking the possibility of resistance through the idea of a 'collective subaltern consciousness', by 1986, consensus on the objectives had dwindled among members of the group. Subsequent to the rapid popularisation of SS in North America in the 1990s where it got absorbed into Humanties departments as an extended form of literary criticism and postcolonial studies (instead of economics or history), and as a consequence of the larger transformations brought about by globalisation, SS 2.0 in its new version came to be seen as a part of 'Indian Cultural Studies'. That SS was partly brewed in a British pot (because it would never have been the project it was, had it not been for Guha's encounter with Thompson, Hobsbawm and other historians interested in the 'history from below' approach in England) is casually glanced past, just as the closure of the Birmingham school is, least the regional and ethnic authenticity of SS come to be at stake. Neither is there very much discussion of the intersectionalities between the 
Subaltern historians and the turbulent British political landscape of the 1980s, which witnessed the rise of an exploitative conservatism under the Tories, accompanied by frequent and violent clashes between the white British population and coloured ethnic minorities, largely from Britain's former colonies. One wonders how the Subaltern historians responded to the violent clashes between ethnic minorities and the police force in Hampstead in 1985, for example, since the very premise of the 'subaltern' extended a warm embrace to a wide range of disenfranchised peoples. What were the conversations between Ranjit Guha and Stuart Hall or Paul Gilroy? Did the solidarities of being immigrants of colour from former British colonies make themselves manifest in the intellectual landscape of Britain through activism across disciplinary formations? It would indeed be worthwhile looking at media archives, university archives, documentary photographs and academic articles to better understand the response from South Asian intellectuals in the UK, to the 1980s ethnic clashes that so strongly marked CS. Without a sense of these (and other such) intertwined histories, we are at a loss for a better understanding of the intersections between the local and the transnational, at least in a pedagogic sense.

\section{Where/What Next?}

In my concluding section, I return to the issue of location and curricula, to emphasise that curricula are documents writ in power and therefore, acts of inclusion and exclusion are political acts. One of the main shifts that led to the emergence of CS was the alienation felt by large sections of society in encountering the texts that narrated their cultural histories, while registering their absence from these texts. At least since the second half of the twentieth century, a large part of humanities scholarship has been a determined response to amend misrepresentations and incomplete narratives, by way of 'deconstructing the canon'. However, the problem with this approach can be that entire courses which attempt to 'deconstruct' the canon, end up being a critique of the fact that there exists a canon, through a constant invocation of canonical texts, even if only to critique them! 
In India, the problem is particularly intense, because of the double whammy of having had to suffer the imposition of the English language, as well as the gradual wiping out of Indian knowledge systems through a British-style education in almost all disciplines. Even while we recognise the monstrous situation we find ourselves in as a consequence of these histories, where we are rapidly losing our ability to read, write and speak fluently in our own languages, we seem to be unable to address these discrepancies within/through the curriculum beyond a critique of the situation. I do not wish to get into the language debate at all here, but do want to point out that the situation is so dire, that by and large, blind emulation of faddish ideas from Anglo-American academies means that 'theory' has begun to be confused with 'knowledge'. In most departments, upscaling the curriculum is seen as injecting larger and larger doses of theory into the syllabus. This crisis seems to be particularly intense in English departments, where theory arrived as a guardian angel to legitimise and make poetry and literature meaningful, and not merely pleasurable. It is quite remarkable that students of literature from the remotest of towns from Kerala to Odisha will have encountered postmodernism and poststructuralism, but are often unable to name a single writer in their own language, or more than three or four Indian writers in English.

Unfortunately, it seems that Literature departments, have struggled with figuring out how to respond to a world where the idea of the literary, as well as its significance are both rapidly shifting. As a consequence of these social and technological transformations, the curricula in many English departments looks like a healthy diet of confusion and irrelevance. Given that the UGC stipulates the number of credits mandatory for a BA or MA programme, there are a limited number of courses that can be offered in a semester, and this means that one needs to select and omit content within a field or discipline. The older notion of a strong curriculum being an exhaustive curriculum, which covers everything that has ever taken place within the discipline seems to neither be feasible nor useful any longer. It may not be far-fetched to say that we are increasingly and rapidly moving back towards a multi-disciplinary world where the narrow specialisations of modern academia seem inadequate. ${ }^{\text {ix }}$ In addition, there is the great uncertainty over the 
future of university education itself in our country, with the changes that are being proposed by the Education Ministry, seemingly without much consultation or study. In this context, it may be an understatement to say that the entire premise and rubric of what constitutes a literary or liberal arts or humanities education itself needs to be revisited, without the shackles of disciplinary chains. CS seems to be among the more poised 'instruments' to take up this challenge, precisely because more than the methods of an emergent quasi-discipline, its critical edge lies within the sharp resonances of undisciplined multi-disciplinarity and embodied practice.

In conclusion, I would like to briefly point out two important

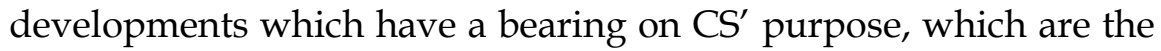
increasing neo-liberalisation of education and the radical social critique emerging within creative fields like visual and performance art. One of the risks of CS becoming institutionalised within contexts that are ideologically and systemically neo-liberal, is that CS then becomes a degree-earning farce, rather than an instrument through which one can critique one's everyday life and immediate surroundings. Resistance to this kind of situation was witnessed a few years ago when the Occupy Academia movement - in which the Visual Cultural theorist, Nicholas Mirzoeff, played a leading part $x$ - advocated holding classes outside University campuses in North America, to protest against increasing fees and privatisation of higher education. The increasing precarity of academic labour along with growing restrictions on academic freedom worldwide, imply that CS in its originally imagined activist form, as a link between the world and the university, is now more necessary than ever.

Combined with this is the fact that criticality risks remaining surficial within academia, if not accompanied by the necessary investment in political action. This is particularly a crisis within the Humanities, where critique has come to stand in for political action and radicalism, without necessitating any 'real world' action on the part of researchers and teachers. On the other hand, increasingly over the last few decades, contemporary visual and performance artists seem to be making a far greater intervention in the social fabric, through work that is collaborative, immersive, and more 
widely accessible. The emerging areas of practice-based research as well as research-driven practice have made it possible to generate work that is grounded in rigorous study, but is not necessarily limited to a discursive 'argument' in the form of a research paper or dissertation alone, and includes written critiques along with other forms of arguments developed as video essays, films, curatorial practice, photography, performance art, and sometimes even dance and musical performances. This makes it imminent for us to consider afresh the relationship between Cultural Studies, Cultural Theory and Cultural Practice, so that the germinal ambition of CS as enmeshed tightly into the lived lives of its practitioners and theorists, rather than as a distant reading echoing the memory of the Birmingham school, can be striven to be kept alive.

\section{References}

Alvares, C. (1979). Homo Faber: technology and culture in India, China and the west. Bombay: Allied Publishers.

Anderson, P. (Jul-Aug 2016). The heirs of Gramsci. New Left Review, 100. Available at https://newleftreview.org/ issues/ II100/ articles/ perry-anderson-the-heirs-of-gramsci [Last accessed 20/06/2019].

Chaturvedi, V. (2000). Mapping Subaltern studies and the postcolonial. New York: Verso Books.

Fanon, F. ([1952] 2017). Black skins, white masks. London: Pluto Press.

Fanon, F. ([1961] 2001). The wretched of the earth. Penguin Modern Classics.

Guha, R. (1982). Subaltern studies I: writings on Indian history and society. New Delhi: OUP.

Guha, R. (1997) A subaltern studies reader (1986-1995). Minneapolis: University of Minnesota Press.

Hall, S. \& Back, L. (July 2009). At home and not at home. Cultural Studies, 23(4), 658-687.

Hall, S. \& Whannel, P. ([1964] 2018). The popular arts. Durham: Duke University Press.

Hall, S. (Jan-Feb 2010). Life and times of the new left review. New Left Review, 61. Available at https:// newleftreview.org/ issues/ II61/ articles/stuart-hall-life-and-times-of-the-first-new-left. [Last Accessed 22/07/2019].

Hsing-Chen, K. (2015). Asia as method. In T. Niranjana \& W. Xiaoming, (Eds.), Genealogies of the Asian present: situating Inter-Asia cultural studies, pp. 57-75. Hyderabad: Orient Blackswan,.

Kothari, R. \& Snell, R. (Eds.). (2011). Chutnifying English: The phenomenon of Hinglish. New Delhi: Penguin. 
Lal, V. (1996). South Asian cultural studies: A bibliography. New Delhi: Manohar Books.

Nandy, A. ([1980] 1995). Alternative sciences: creativity and authenticity in two Indian scientists. New Delhi: OUP.

Niranjana, T. \& Xiaoming, W. (Eds.) (2015). Genealogies of the Asian present: situating Inter-Asia cultural studies. Hyderabad: Orient Blackswan.

Prasad, M. (2015). Cultural studies in India. In T. Niranjana \& W. Xiaoming, (Eds.), Genealogies of the Asian present: situating Inter-Asia cultural studies, $p p$. 153-70. Hyderabad: Orient Blackswan,.

Radhakrishnan, R. (2008). Cultural studies in India: A preliminary report on institutionalisation. Bangalore: CSCS.

Said, E. (1978). Orientalism. New York: Pantheon Books.

Sardar, Z. \& Van Loon, B. (1998). introducing cultural studies: A graphic guide. Michigan: Totem Books.

Sarkar, S. (1968). The thoughts of Gramsci. Mainstream, 7, 17-26.

Tamari, T. (2006). Cultural studies in Japan: An interview with Shyunya Yoshimi. Theory, Culture \& Society, 23(7-8), 305-314.

Tharu, S. (2012). Problematics of the popular in contemporary India. Available at https://www.mixcloud.com/IndiaIFA/susie-tharu-problematicsof-the-popular-in-contemporary-india/. [Last accessed 9/06/2019].

Thompson, E.P. (1963). The making of the English working class. New York: Vintage Books.

Uberoi, J. S. (1978). Science and culture. New Delhi: OUP.

William, R. ([1958] 1983). Culture and society. New York: Columbia University Press.

\section{Endnotes}

iDespite Raymond Williams being Welsh, much of his contribution to Media, Literary and Cultural Studies are seen as being representative of an 'English working class', the distinctiveness of Welshness being subsumed under a larger 'national' identity.

iiThe semantics of the terms Indian Cultural Studies and Cultural Studies in India paint two very different pictures, the complexities of which I will avoid getting into for now. Suffice it to say that what I mean by the use of these terms is a practice and theory of Cultural Studies, as it is developed both within India as well as outside India, but relating to the Indian context.

iii Available at https://www.mixcloud.com/IndiaIFA/susie-tharuproblematics-of-the-popular-in-contemporary-india/. Last accessed 9/06/2019. 
iv Journal website available at https:// www.tandfonline.com/ action/journal Information?show=aimsScope\&journalCode=riac20. [Last accessed 20 June 2019].

v "It should by now be clear that, even within the editorial boards of the original journals, the New Left was far from monolithic and certainly never became culturally or politically homogeneous. The tensions were, for the most part, humanely and generously handled. But any careful reader of the journals will quickly be able to identify real points of difference and, on occasion, fiercely contended debates surfacing in their pages. It would therefore be quite wrong to attempt to reconstruct, retrospectively, some essential 'New Left', and to impose on it a political unity it never possessed. Nevertheless, although no two members would offer the same list, there was a set of linked themes which commanded wide enough assent to make it distinctive as a political formation." (Hall 2010: 185)

vi Vinayak Chaturvedi charts out the formative influences on Guha's work in the Introduction to Mapping the Postcolonial (2000: i-xix)

viiPerry Anderson chronicles the tremendous global influence of Gramsci in his article "The Heirs of Gramsci". Available at https:// newleftreview.org/issues/II100/articles/perry-anderson-the-heirs-ofgramsci [Last accessed 20 June 2019].

viiiIt has been a long-standing criticism of the Communist Party of India (in all its various avatars and editions) that the Left has been quite remarkably blind to gender and caste, and has by and large pretended that both these aspects do not intersect with class at all.

ix There is a significant body of work on the history of the university to indicate that the division into modern disciplines is a relatively recent phenomenon, which to some extent has become part of the internal logic of job creation, by periodically establishing new departments and specialisations.

xI specifically mention Nicholas Mirzoeff as he is a great example of combing scholarship with activism, reshaping institutional structures and practices through creative and embodied action demanding transformation. Occupy Academia is one such example. A better sense of his approach can be gained from reading his commentary on the Visual Cultural Studies Readers here https:// www.nicholasmirzoeff.com/O2012/2012/07/30/after-visual-culture/. [Last accessed 24/07/2019] 